\title{
Acute changes in blood metabolites and amino acid profile post-exercise in Foxhound dogs fed a high endurance formula*
}

\author{
Maria R. C. de Godoy ${ }^{1 \dagger}$, Alison N. Beloshapka ${ }^{1}$, Rebecca A. Carter ${ }^{3}$, Andrea J. Fascetti ${ }^{4}$, Zengshou Yu ${ }^{4}$, \\ Bridgett J. McIntosh ${ }^{5}$, Kelly S. Swanson ${ }^{1,2}$ and Preston R. Buff ${ }^{3}$ \\ ${ }^{1}$ Department of Animal Sciences, University of Illinois, Urbana, IL 61801, USA \\ ${ }^{2}$ Division of Nutritional Sciences, University of Illinois, Urbana, IL 61801, USA \\ ${ }^{3}$ The Nutro Company, Franklin, TN 37067, USA \\ ${ }^{4}$ Department of Molecular Biosciences, School of Veterinary Medicine, University of California, Davis, CA 95616, USA \\ ${ }^{5}$ Department of Animal Science, University of Tennessee, Knoxville, TN 37996, USA
}

(Received 23 January 2014 - Final revision received 28 April 2014 - Accepted 5 June 2014)

Journal of Nutritional Science (2014), vol. 3, e33, page 1 of 6

doi:10.1017/jns.2014.46

Abstract

Dogs participating in endurance exercise, including herding, hunting and racing have a greater energy requirement and may be more susceptible to nutrient depletion, electrolyte imbalance and metabolic stress. The objective of the present study was to investigate the acute response to unstructured mixed exercise in American Foxhounds fed a nutrient-fortified endurance diet. Thirty-nine adult Foxhound dogs (median age: 5.0, range: 2-10 years and median body weight (BW): 36.4, range: $24 \cdot 9-49.5 \mathrm{~kg}$ ) were allotted to a standard performance diet (Control) or nutrient-fortified endurance diet for adult dogs (Test). Dogs were balanced by sex, age, BW and athletic performance between diets. All male dogs were intact, whereas all the female dogs were spayed. After $80 \mathrm{~d}$ on diet, blood samples were collected via jugular puncture at baseline $(0 \mathrm{~h}$ ), and at 3 and $25 \mathrm{~h}$ post-exercise (mean: 17.7 (SEM 0.92) km run over 2-3 h). Plasma taurine concentration and complete amino acid (AA) profile, serum chemistry and creatine kinase were measured. Serum chemistry profile remained within normal ranges throughout the study. A significant $(P<0.05)$ diet by time interaction was observed for calcium, alkaline phosphatase and most AA. Plasma taurine and most essential AA were increased $(P<0.05)$ after exercise and remained greater $(P<0.05)$ in dogs fed the Test diet, including the branched-chain AA (isoleucine, leucine and valine). Creatine kinase increased $(P=0.01)$ after $3 \mathrm{~h}$ and returned to baseline after $25 \mathrm{~h}$ post-exercise, but was not altered by diet. These data indicate that dogs undergoing a moderate bout of exercise did not suffer from electrolyte imbalance, and that a nutrient-fortified diet resulted in greater plasma taurine and essential AA concentrations.

Key words: Canine: Exercise: Oxidative stress: Performance

Athlete dogs have a greater energy requirement than adult dogs during periods of normal maintenance ${ }^{(1)}$. Endurance exercise, characterised by prolonged periods of exercise at submaximal levels of exertion, relies mostly on aerobic metabolism using fat as the primary source of energy. During shorter bouts of greater intensity exercise a shift towards anaerobic metabolism occurs and carbohydrate metabolism becomes important to maintain performance ${ }^{(2)}$. Electrolyte balance and metabolic stress are important nutritional considerations for canine athletes, as some minerals can become depleted and a greater oxidative rate can affect their performance and health.

Exercise increases the body's production of free radicals and markers of oxidation, while antioxidant concentration depletes them. Therefore, dietary supplementation with antioxidants may have a protective effect against oxidative stress ${ }^{(3)}$.

Abbreviations: AA, amino acids; BCAA, branched-chain amino acids; BW, body weight; CK, creatine kinase.

†Corresponding author: Maria R. Cattai de Godoy, fax + 1217333 7861, email mgodoy2@illinois.edu

* This article was published as part of the WALTHAM International Nutritional Sciences Symposium Proceedings 2013. 
Dietary protein, including amino acids (AA), are important to minimise striated muscle tissue damage during exercise and thus support athletic performance. The provision of a wellbalanced, high-quality diet is necessary to improve endurance and health of athlete dogs. The objective of the present study was to investigate the acute response to unstructured mixed exercise in American Foxhounds fed a nutrient-fortified high endurance diet.

\section{Material and methods}

\section{Animals, diets and housing}

Forty adult Foxhound dogs (thirty-two intact males and seven spayed females) with a median age: 5.0 years (range: 2-10 years) and median body weight (BW): $36.4 \mathrm{~kg}$ (range: 24.9 $49.5 \mathrm{~kg}$ ) were used in the present experiment. Power analysis was performed to determine the necessary number of dogs per treatment, using a power of 0.8 and alpha of 0.05 . According to values reported by Dunlap et al. ${ }^{(4)}$ for plasma creatine kinase $(\mathrm{CK})$, an SD two times greater than the observed by these authors was assumed for the determination of minimum sample size in the present study. The power analysis indicated a sample size of twenty dogs per treatment. One dog was removed for medical reasons unrelated to the study and its data were removed from statistical analysis. Dogs were group housed throughout the trial, separated by dietary treatment and sex. During the day, all dogs were allowed $8 \mathrm{~h}$ in a play yard, which had an approximate dimension of $18 \mathrm{~m} \times 21 \mathrm{~m}$. All dogs had $30 \mathrm{~min}$ of human interaction as social enrichment daily as a group. The outdoor runs contained trees for shade, or covered, raised platforms. At night, and in inclement weather, all dogs were housed in a lodge, which allowed access to the outdoors should dogs prefer it. Suspended platforms and beds were available for animals in the lodge area. The indoor facility had natural and artificial lighting and was equipped with fans for comfort if needed. An artificial light:dark cycle of $12: 12 \mathrm{~h}$ was used to allow early morning feeding $(05.00 \mathrm{~h})$ and handling the animals until later in the evening $(17.00 \mathrm{~h})$. The animal facility and play yard were cleaned daily. The facility and all experimental methods were approved by the Waltham Centre for Pet Nutrition Animal Ethics and Welfare Committee and an informed consent was received by the owner of the kennel (Hard Away Whitworth Hounds) and dogs prior to experimentation. During the experiment, the low and high daily environmental temperature was 3.9 and $24.4^{\circ} \mathrm{C}$, respectively.

Animals were assigned to one of two groups; a Control diet (standard commercial performance diet; $n$ 19) or a Test diet (nutrient-fortified endurance diet for adult dogs; $n 20$ NUTRO $^{\circledR} \quad$ NATURAL CHOICE ${ }^{\circledR}$ High Endurance Chicken Meal Whole Brown Rice \& Oatmeal Formula). The Test diet provided about $73.6 \mathrm{~g}$ of protein, $52.9 \mathrm{~g}$ of fat/ $4814 \mathrm{~kJ}$ metabolisable energy $(1 \mathrm{kcal}=4 \cdot 184 \mathrm{~kJ})$, and had a metabolisable energy of $18.7 \mathrm{~kJ} / \mathrm{g}$ - calculated based on $\mathrm{NRC}^{(5)}$, whereas the Control diet provided $65 \cdot 7,51 \cdot 0 \mathrm{~g}$ of protein and fat $4814 \mathrm{~kJ}$ and a metabolisable energy of $17.9 \mathrm{~kJ} / \mathrm{g}-$ calculated based on $\mathrm{NRC}^{(5)}$, respectively. Complete listing of ingredients and nutrient composition of Control and Test diets are presented in Supplementary Table 1 - online. Animals were systematically allotted between groups to match for age, sex, BW and past performance (good, moderate, poor and unknown) to ensure an even distribution across both groups. Dogs were group fed once a day to maintain ideal BW and ration was adjusted as needed during the study between 13389 and $15480 \mathrm{~kJ} / \mathrm{dog}$. Ideal BW was based off previous feeding records, breed standards and BCS using a nine-point scale ${ }^{(6)}$. Water was available ad libitum.

\section{Blood collection, handling and analyses}

Venous blood samples $(20 \mathrm{ml})$ were collected via jugular venipuncture at baseline $(0 \mathrm{~h})$, and at 3 and $25 \mathrm{~h}$ post-exercise into sodium heparin- or serum-separating tube-vacutainer blood tubes (Becton Dickson). Heparin-vacutainer tubes were immediately placed on ice for approximately $30 \mathrm{~min}$. Heparin and serum tubes were centrifuged at $1240 \mathrm{~g}$ for $10 \mathrm{~min}$ at $4^{\circ} \mathrm{C}$. Serum, plasma and blood samples were stored at $-80^{\circ} \mathrm{C}$ for plasma $\mathrm{AA}$ and MDA analyses, and $-20^{\circ} \mathrm{C}$ for serum chemistry and CK determination. Blood and plasma taurine concentrations, and complete AA profile were analysed within $15 \mathrm{~d}$ of blood collection, using a norleucine standard and an automated AA analyser (HPLC, Biochrom 30, Biochrom Ltd) at the Amino Acid Laboratory at the University of California, Davis $^{(7)}$. Half a millilitre of $6 \%$ sulphosalicylic acid was added to $0.5 \mathrm{ml}$ of plasma to precipitate the plasma proteins. All AA results were reported as $\mathrm{nmol} / \mathrm{ml}$ of plasma or whole blood. Plasma MDA concentrations were determined within 1 month of blood collection, by MP Biomedicals using commercial kit (SafTest ALDESAFE ${ }^{\mathrm{TM}}$, product no. 07KTAC1010) developed based on the method by Hamilton $\&$ Rossell $^{(8)}$. Serum tubes were kept at room temperature. Serum chemistry (creatinine, blood urea nitrogen, total protein, albumin, calcium, potassium, chloride, corticosteroid-induced alkaline phosphatase, alkaline phosphatase, alanine aminotransferase, gamma-glutamyl transpeptidase, total bilirubin, cholesterol, TAG, $\mathrm{CO}_{2}$ and glucose) and $\mathrm{CK}$ were determined within 1 week of blood collection, using a Hitachi 911 clinical chemistry analyser (Roche Diagnostics; University of Illinois Veterinary Medicine Diagnostics Laboratory).

\section{Exercise regimen and GPS measurements}

The exercise regimen consisted of a bout of 2-3 h of unstructured mixed exercise that simulated a chasing or herding field exercise. Dogs were evenly assigned to two groups by dietary treatment and completed the bout of exercise on one of two consecutive days. All animals were maintained on respective dietary treatments (Control or Test diet) for $80 \mathrm{~d}$ and were exercised weekly prior to exercise data collection. Dogs were acclimated to wearing GPS collars (DC 40, Garmin Ltd.) prior to data collection day. Activity data were collected using Astro 320 Global Positioning System (Garmin Ltd.). Because GPS coordinates were provided every $15 \mathrm{~s}$, distance travelled and the time required were obtained and used to calculate total miles run and speeds per dog. The maximum 
speed was based on the intermittent measurements of distance obtained in a set length of time (e.g. every $15 \mathrm{~s}$ ). Maximum average speed was considered to be the point of $80 \%$ of maximum speed.

\section{Statistical analysis}

Data from blood metabolites were analysed as repeated measurements using Mixed procedure of SAS (version 9.3, SAS Inst., Inc., Cary, NC). The statistical model included fixed effect of diet, time and their interaction and random effect of animal. The GPS data were analysed using Mixed procedure of SAS. Data normality was checked using the UNIVARIATE procedure of SAS. All treatment least-squares means were compared with each other and Tukey adjustment was used to control for experiment-wise error. Differences between means with $P<0.05$ were considered significant. Data are presented as means with their standard errors.

\section{Results}

\section{Blood metabolites and amino acid profile}

Serum chemistry profile was within reference range for dogs fed the Control or Test diet (Table 1). A significant diet by time interaction was observed for calcium and alkaline phosphatase concentrations. Serum calcium concentration decreased post-exercise in dogs fed the Control and the Test diet and was lowest after $25 \mathrm{~h}$ of exercise for dogs being fed the Test diet $(P=0 \cdot 01)$. Post acute-exercise, an increased concentration of alkaline phosphatase was observed only in dogs fed the Test $(P=0 \cdot 01)$. A significant diet effect was noted for blood urea nitrogen $(P=0.01)$, phosphorus $(P=0.04)$, chloride $(P=0.02)$, cholesterol $(P=0.01)$ and $\mathrm{CO}_{2}(P=0 \cdot 01)$ serum concentrations. Similarly, most of the serum metabolites were affected by time, except for alanine aminotransferase $(P=0.07)$, gamma-glutamyl transpeptidase $(P=0.33)$ and MDA $(P=0.77)$. Among the variables affected by time, serum $\mathrm{CK}$, an indirect marker of muscle damage, was sharply increased $3 \mathrm{~h}$ post-exercise $(P=0 \cdot 01)$, but it remained within physiological range and returned to baseline concentration at $25 \mathrm{~h}$ post-exercise. Plasma MDA, an indirect marker of oxidative stress and lipid peroxidation, did not differ prior to or post-exercise in $\operatorname{dogs}$ fed Control or Test $\operatorname{diet}(P=0.89$; Table 1).

A significant diet by time interaction was observed for most of the AA analysed, except for arginine $(P=0.52)$, phenylalanine $(P=0.16)$, aspartic acid $(P=0.30)$, glutamic acid $(P=0.87)$, glutamine $(P=0 \cdot 14)$, hydroxyproline $(P=0.82)$, amino butyric-acid $(P=0.08)$, cystathionine $(P=0.67)$ and 2-methyl-L-histidine $(P=0 \cdot 22$; Table 2). In general, essential AA plasma concentrations were increased after exercise and in animals fed the Test diet; isoleucine $(P=0.01)$, leucine $(P=0.01)$, lysine $(P=0 \cdot 01)$, methionine $(P=0 \cdot 01)$, threonine $(P=0 \cdot 01)$ and valine $(P=0 \cdot 01)$; in comparison with AA concentrations prior to exercise and/or from animals fed the Control diet. A similar pattern was observed for some non-essential AA. Plasma taurine concentration was greater $(P=0.01)$ prior to and post-exercise in dogs fed the Test diet in comparison with AA concentrations prior to exercise and/or from animals fed the Control diet. Plasma carnosine also was increased $(P=0.01)$ in dogs fed the Test diet at $25 \mathrm{~h}$ post-exercise when compared with dogs fed the Control diet.

A significant diet by time $(\mathrm{D} \times \mathrm{T})$ interaction was observed for plasma branched-chain amino acid (BCAA) and tryptophan concentrations $(P=0 \cdot 01$; Table 2$)$. For the BCAA:tryptophan ratio data, there was only a significant effect of diet, with the Test diet having a greater $(P=0.02)$ ratio when compared with the Control diet $(6 \cdot 1 \pm 0 \cdot 24 v \cdot 5 \cdot 3 \pm 0 \cdot 25)$.

\section{Athletic performance}

Distance run $(\mathrm{km})$, average speed $(\mathrm{km} / \mathrm{h})$ and maximum speed $(\mathrm{km} / \mathrm{h})$ during the exercise bout did not differ $(P=0.48,0.84$ and 0.79 , respectively) between $\operatorname{dogs}$ fed the Control (17.1 $(0.91) \mathrm{km} ; 9(0.37) \mathrm{km} / \mathrm{h} ; 36.3(2.0) \mathrm{km} / \mathrm{h}$, respectively) and Test $(18 \cdot 6(0 \cdot 93) \mathrm{km} ; 9(0 \cdot 37) \mathrm{km} / \mathrm{h} ; 37 \cdot 1(2 \cdot 0) \mathrm{km} / \mathrm{h}$, respectively) diets.

\section{Discussion}

The present study examined the acute response to unstructured mixed exercise in American Foxhounds fed a nutrientfortified endurance diet on blood metabolites, plasma indirect oxidative marker and athletic performance. Serum chemistry results indicated that all dogs were healthy prior and postexercise. Even though some metabolites changed due to exercise, diet or their combination, they were still within reference range of healthy animals. Increased plasma or serum concentration of CK following physical activity has been associated with muscle damage that can result in soreness, decreased range of motion, swelling and performance decline ${ }^{(9)}$. In human athletes, elevated plasma CK concentration up to $5 \mathrm{~d}$ post-exercise has been observed $^{(9)}$. In sled dogs, plasma CK activity was significantly increased post-exercise and incremental increase in CK was observed from day 1 (519 U/l) of exercise when compared with days 2 and 3 (2332 and $2487 \mathrm{U} / 1$, respectively ${ }^{(3)}$. In that study, a group of dogs received daily antioxidant supplementation $(457 \mathrm{mg}$ of vitamin $\mathrm{E}, 706 \mathrm{mg}$ of vitamin $C$ and $5.1 \mathrm{mg}$ of $\beta$-carotene), however antioxidant supplementation failed to attenuate an exercise-induced increase in CK activity ${ }^{(3)}$. This outcome is in agreement with the present study, where no beneficial effect in plasma CK attenuation was observed with the provision of a nutrientfortified diet for athlete dogs.

Differently than hypothesised, plasma MDA concentration was not affected by diet or exercise. Even though aerobic exercise leads to a greater consumption of oxygen, and as a consequence an increase in free radical production ${ }^{(3)}$, the Control and the Test diet must have provided sufficient antioxidants that protected these animals from oxidative stress. Another possibility is that the exercise regimen was not severe enough to challenge the animals' oxidative rate. Previous research has reported plasma MDA concentration for adult healthy dogs to range from 5 to $11 \mu \mathrm{mol} / \mathrm{l}^{(10)}$. Therefore, in the present study, dogs from Control and Test diets pre- and post-exercise were within the range reported for healthy dogs. 
Table 1. Serum chemistry, creatine kinase and malondialdehyde concentrations prior to and 3 or $25 \mathrm{~h}$ post-exercise in American Foxhound dogs fed a Control or Test diet

\begin{tabular}{|c|c|c|c|c|c|c|c|c|c|c|c|}
\hline \multirow[b]{3}{*}{ Item* } & \multirow[b]{3}{*}{ Reference range } & \multicolumn{6}{|c|}{ Treatments } & \multirow[b]{3}{*}{ SEM } & \multirow{2}{*}{\multicolumn{3}{|c|}{$P$}} \\
\hline & & \multicolumn{3}{|c|}{ Control } & \multicolumn{3}{|c|}{ Test } & & & & \\
\hline & & $\mathrm{Oh}$ & $3 \mathrm{~h}$ & $25 \mathrm{~h}$ & $\mathrm{Oh}$ & $3 \mathrm{~h}$ & $25 \mathrm{~h}$ & & Diet & Time & $\mathrm{D} \times \mathrm{T}$ \\
\hline CRE $(\mu \mathrm{mol} / \mathrm{l})$ & $44 \cdot 2-132 \cdot 6$ & 88.2 & 79.6 & 85.7 & 81.3 & 84.0 & 91.1 & 0.03 & 0.38 & 0.01 & 0.21 \\
\hline BUN $(\mathrm{mm} / \mathrm{l})$ & $2 \cdot 1-10 \cdot 7$ & $6 \cdot 8$ & 5.9 & $7 \cdot 3$ & $7 \cdot 1$ & 6.5 & 8.4 & 0.71 & 0.01 & 0.01 & 0.08 \\
\hline TP (g/l) & $51 \cdot 0-70 \cdot 0$ & 68.6 & $70 \cdot 6$ & 68.8 & 70.6 & $71 \cdot 2$ & $69 \cdot 3$ & 0.13 & 0.55 & 0.01 & 0.21 \\
\hline ALB (g/l) & $0.03-0.04$ & 0.03 & 0.03 & 0.03 & 0.03 & 0.03 & 0.03 & 0.06 & 0.79 & 0.01 & 0.36 \\
\hline $\mathrm{Ca}(\mathrm{mm} / \mathrm{l})$ & $1.9-2.9$ & $2 \cdot 6^{\mathrm{a}}$ & $2 \cdot 5^{\mathrm{b}}$ & $2 \cdot 5^{\mathrm{b}}$ & $2 \cdot 5^{\mathrm{a}}$ & $2 \cdot 5^{\mathrm{b}}$ & $2 \cdot 4^{\mathrm{c}}$ & 0.04 & 0.46 & 0.01 & 0.01 \\
\hline$P(\mathrm{~mm} / \mathrm{l})$ & $0.9-1.7$ & 1.5 & 1.5 & 1.3 & 1.6 & 1.5 & 1.5 & 0.06 & 0.04 & 0.01 & 0.11 \\
\hline $\mathrm{Na}(\mathrm{mm} / \mathrm{l})$ & $141-152$ & 144.21 & 143.89 & $145 \cdot 32$ & 144.55 & 143.75 & $145 \cdot 15$ & 0.48 & 0.98 & 0.01 & 0.81 \\
\hline $\mathrm{K}(\mathrm{mm} / \mathrm{l})$ & $3.9-5.5$ & 4.3 & 4.0 & 4.2 & 4.3 & 4.2 & 4.4 & 0.06 & 0.01 & 0.01 & 0.10 \\
\hline $\mathrm{Cl}(\mathrm{mm} / \mathrm{l})$ & $107-118$ & 109.84 & $106 \cdot 58$ & 109.47 & 110.45 & 109.65 & 111.45 & 0.73 & 0.02 & 0.01 & 0.08 \\
\hline CIALP (U/I) & & $1.63^{\mathrm{c}}$ & $1.37^{c}$ & $1.90^{\mathrm{C}}$ & $2 \cdot 9^{b c}$ & $3.60^{b}$ & $4 \cdot 25^{a}$ & 0.91 & 0.13 & 0.01 & 0.01 \\
\hline $\operatorname{ALP}(\mathrm{U} / \mathrm{l})$ & 7-92 & $33.42^{c}$ & $35 \cdot 32^{c}$ & $39.68^{c}$ & $44.50^{c}$ & $49 \cdot 65^{b}$ & $60 \cdot 60^{a}$ & 3.67 & 0.01 & 0.01 & 0.01 \\
\hline $\operatorname{ALT}(\mathrm{U} / \mathrm{l})$ & $8-65$ & 34.90 & 37.05 & 33.79 & 37.05 & $46 \cdot 45$ & 41.35 & 3.42 & 0.09 & 0.07 & 0.39 \\
\hline GGT (U/I) & $0-7$ & 1.63 & 1.37 & 1.68 & 1.25 & 1.30 & 1.45 & 0.19 & 0.25 & 0.33 & 0.61 \\
\hline TBIL $(\mu \mathrm{mol} / \mathrm{l})$ & $1 \cdot 7-5 \cdot 1$ & $2 \cdot 2$ & 2.9 & $2 \cdot 6$ & $2 \cdot 2$ & $2 \cdot 7$ & $2 \cdot 4$ & 0.17 & 0.55 & 0.01 & 0.79 \\
\hline $\mathrm{CHOL}(\mathrm{mm} / \mathrm{l})$ & $3 \cdot 3-7 \cdot 7$ & 4.4 & 4.3 & 4.5 & 3.9 & 3.8 & 3.9 & 0.16 & 0.01 & 0.01 & 0.47 \\
\hline $\mathrm{TAG}, \mathrm{mm} / \mathrm{l}$ & $0.4-1.7$ & $0.6^{\mathrm{bc}}$ & $0.5^{\mathrm{c}}$ & $0.8^{\mathrm{ab}}$ & $0.5^{\mathrm{c}}$ & $0.6^{c}$ & $1 \cdot 0^{\mathrm{a}}$ & 0.06 & 0.61 & 0.01 & 0.03 \\
\hline $\mathrm{CO}_{2}, \mathrm{~mm} / \mathrm{l}$ & $16-24$ & $27 \cdot 05$ & $25 \cdot 63$ & $24 \cdot 11$ & 24.60 & 23.55 & 21.00 & 0.42 & 0.01 & 0.01 & 0.45 \\
\hline GLUCOSE (mм/l) & $3.8-7.0$ & $5 \cdot 0$ & 5.9 & $5 \cdot 3$ & 4.9 & 5.5 & $5 \cdot 1$ & 0.12 & 0.05 & 0.01 & 0.58 \\
\hline CK (U/l) & $26-791$ & $168 \cdot 42$ & $490 \cdot 42$ & 142.63 & 149.00 & $445 \cdot 35$ & 115.25 & $44 \cdot 17$ & 0.39 & 0.01 & 0.94 \\
\hline MDA $(\mu \mathrm{mol} / \mathrm{l})$ & & 7.37 & 6.71 & 6.96 & 6.97 & 6.83 & 6.87 & 0.55 & 0.80 & 0.77 & 0.89 \\
\hline
\end{tabular}

${ }^{\mathrm{a}-\mathrm{c}}$ Within a row, means without a common letter differ (diet $\times$ time interaction; $\left.P<0.05\right), n 39$.

${ }^{*}$ Creatinine $=\mathrm{CRE}$, blood urea nitrogen $=\mathrm{BUN}$, total protein $=\mathrm{TP}$, albumin $=\mathrm{ALB}$, calcium $=\mathrm{Ca}$, phosphorus $=\mathrm{P}$, potassium $=\mathrm{K}$, chloride $=\mathrm{Cl}$, corticosteroid-induced alkaline phosphatase $=\mathrm{CIALP}$, alkaline phosphatase $=\mathrm{ALP}$, alanine aminotransferase $=\mathrm{ALT}$, gamma-glutamyl transpeptidase $=\mathrm{GGT}$, total bilirubin $=\mathrm{TBIL}$, cholesterol $=\mathrm{CHOL}$, carbon dioxide $=\mathrm{CO}_{2}$, creatine kinase $=\mathrm{CK}$, malondialdehyde $=$ MDA.

In the present study, the greater plasma and blood taurine concentrations of dogs fed the Test diet was likely a consequence of increased dietary taurine content. Taurine is important for maintenance of cardiac function, which is fundamental for maintenance of animals' health and athletic performance ${ }^{(7)}$. In the present study, all dogs had plasma and whole blood taurine concentrations above low critical values (concentrations considered near to cause a nutrient deficiency) reported in the literature for adult healthy dogs $(40$ and $150 \mathrm{nmol} / \mathrm{ml}$, respectively) ${ }^{(7)}$. However, three dogs from the Control group had plasma taurine concentration close to the minimal critical value $(40 \mathrm{nmol} / \mathrm{ml})$. Overtime and with continuous exercise, these animals could be at greater risk to develop taurine deficiency, suggesting that canine athletes might conditionally require dietary taurine; however, this hypothesis requires further investigation.

Increased concentration of plasma carnosine has a potentially ergogenic effect; enhancing buffering capacity in skeletal muscle ${ }^{(11)}$. In addition, racing dogs (Greyhounds) have greater intramuscular carnosine concentration ${ }^{(12)}$, probably a protective mechanism to avoid exercise-induced acidosis during anaerobic exercise. The increased plasma carnosine concentration observed at $25 \mathrm{~h}$ post-exercise in dogs fed the Test diet was not associated with improved athletic performance in the present study, however.

Maintenance of greater plasma BCAA concentrations postexercise may aid animals to recover faster, because these AA are involved in protein synthesis, energy supply for skeletal muscle and suppression of lactate concentration in muscle during exercise $\mathrm{e}^{(13-15)}$. Increased BCAA:tryptophan ratio has been previously related to delay mental and physical fatigue during sustained heavy exercise ${ }^{(16,17)}$. Among the BCAA, leucine is primarily involved with protein synthesis ${ }^{(18)}$. In the present study, plasma leucine concentration was increased post-exercise in dogs fed the Test diet. However, no differences in exercise performance (distance run, and average and maximum speed) were observed between dogs fed the Control $v$. the Test diet after a bout of unstructured mixed exercise. Future studies are warranted to investigate the effects of more strenuous exercise regimens on the plasma BCAA concentrations of exercising dogs and their potential benefits in delaying fatigue and mitigating muscle damage. Despite some of the benefits of feeding the Test diet (e.g. increased plasma taurine, carnosine and BCAA concentrations) no improvement in athletic performance was observed between dogs fed the Control or Test diets, which indicates that both diets were adequate to maintain athletic performance and health of dogs undergoing unstructured mixed exercise.

Some of the limitations associated with this field study are that not all parameters investigated could be as tightly controlled as in a research facility. In the present study, some of the limitations included the inability to measure individual food intake, which limits the data interpretation because the effect of diet cannot be separated from hierarchical dominance during feeding. In addition, the unstructured exercise regimen may not have challenged all animals in the same manner. A structured, longer and more intense exercise regimen could have been beneficial; however it would not reflect the freerange exercise of a hunting dog. Variations in age and athletic performance might also have restricted our ability to detect 
Table 2. Amino acid profile prior to and 3 or $25 \mathrm{~h}$ post-exercise of American Foxhound dogs fed a Control or Test diet

\begin{tabular}{|c|c|c|c|c|c|c|c|c|c|c|}
\hline \multirow[b]{3}{*}{$\mathrm{AA}(\mathrm{nmol} / \mathrm{ml})$} & \multicolumn{6}{|c|}{ Treatments } & \multirow[b]{3}{*}{ SEM } & \multirow{2}{*}{\multicolumn{3}{|c|}{$P$}} \\
\hline & \multicolumn{3}{|c|}{ Control } & \multicolumn{3}{|c|}{ Test } & & & & \\
\hline & $\mathrm{Oh}$ & $3 \mathrm{~h}$ & $25 \mathrm{~h}$ & $\mathrm{Oh}$ & $3 \mathrm{~h}$ & $25 \mathrm{~h}$ & & Diet & Time & $\mathrm{D} \times \mathrm{T}$ \\
\hline WB Taurine & $379.6^{c}$ & $431.1^{c}$ & $353.0^{\mathrm{b}}$ & $475.0^{\mathrm{b}}$ & $608 \cdot 5^{\mathrm{a}}$ & $482 \cdot 7^{\mathrm{b}}$ & 19.69 & 0.01 & 0.01 & 0.01 \\
\hline Plasma Taurine & $61 \cdot 8^{c}$ & $78 \cdot 8^{\mathrm{c}}$ & $73.9^{c}$ & $152 \cdot 1^{\mathrm{b}}$ & $229.6^{a}$ & $173 \cdot 3^{b}$ & 9.07 & 0.01 & 0.01 & 0.01 \\
\hline \multicolumn{11}{|l|}{ Essential } \\
\hline Arginine & 137.6 & $147 \cdot 9$ & 137.4 & 155.9 & $175 \cdot 0$ & $168 \cdot 7$ & $6 \cdot 31$ & 0.01 & 0.06 & 0.52 \\
\hline Histidine & $82 \cdot 2^{b c}$ & $96 \cdot 8^{\mathrm{a}}$ & $80 \cdot 2^{c}$ & $85 \cdot 1^{\mathrm{bc}}$ & $98.1^{\mathrm{a}}$ & $92 \cdot 1^{\mathrm{ab}}$ & 2.62 & 0.06 & 0.01 & 0.01 \\
\hline Isoleucine & $56 \cdot 8^{\mathrm{C}}$ & $71 \cdot 5^{\mathrm{b}}$ & $61.9^{\mathrm{bc}}$ & $70 \cdot 8^{\mathrm{b}}$ & $102 \cdot 9^{a}$ & $94 \cdot 4^{a}$ & $2 \cdot 70$ & 0.01 & 0.01 & 0.01 \\
\hline Leucine & $132 \cdot 2^{c}$ & $155 \cdot 7^{\mathrm{b}}$ & $146 \cdot 6^{\mathrm{bc}}$ & $134.3^{\mathrm{c}}$ & $190 \cdot 6^{\mathrm{a}}$ & $178 \cdot 4^{\mathrm{a}}$ & 4.46 & 0.01 & 0.01 & 0.01 \\
\hline Lysine & $104 \cdot 0^{c}$ & $159 \cdot 4^{\mathrm{b}}$ & $116 \cdot 0^{\mathrm{C}}$ & $145 \cdot 1^{\mathrm{b}}$ & $208 \cdot 6^{\mathrm{a}}$ & $191 \cdot 6^{\mathrm{a}}$ & 6.51 & 0.01 & 0.01 & 0.01 \\
\hline Methionine & $81 \cdot 5^{b}$ & $74.2^{\mathrm{b}}$ & $84.5^{\mathrm{b}}$ & $77 \cdot 0^{\mathrm{b}}$ & $85 \cdot 2^{\mathrm{b}}$ & $103 \cdot 9^{a}$ & 3.28 & 0.01 & 0.01 & 0.01 \\
\hline Phenylalanine & $54 \cdot 1$ & $63 \cdot 8$ & $56 \cdot 6$ & 52.9 & $71 \cdot 1$ & 58.4 & $2 \cdot 30$ & 0.24 & 0.01 & 0.16 \\
\hline Threonine & $243 \cdot 6^{b}$ & $229.0^{\mathrm{b}}$ & $227 \cdot 2^{\mathrm{b}}$ & $252.5^{\mathrm{b}}$ & $242 \cdot 7^{b}$ & $302 \cdot 0^{\mathrm{a}}$ & $13 \cdot 12$ & 0.05 & 0.01 & 0.01 \\
\hline Tryptophan & $70 \cdot 7^{b}$ & $93 \cdot 2^{\mathrm{a}}$ & $82 \cdot 3^{a}$ & $66 \cdot 1^{\mathrm{b}}$ & $96 \cdot 8^{\mathrm{a}}$ & $96 \cdot 3^{a}$ & 3.88 & 0.31 & 0.01 & 0.01 \\
\hline Valine & $179 \cdot 1^{d}$ & $228 \cdot 4^{\mathrm{b}}$ & $215.0^{\mathrm{bc}}$ & $198 \cdot 7^{\mathrm{cd}}$ & $270 \cdot 6^{a}$ & $275 \cdot 1^{\mathrm{a}}$ & $6 \cdot 71$ & 0.01 & 0.01 & 0.01 \\
\hline \multicolumn{11}{|l|}{ Non-essential } \\
\hline Alanine & $362 \cdot 2^{b}$ & $478 \cdot 0^{\mathrm{a}}$ & $356 \cdot 9^{b}$ & $370 \cdot 7^{b}$ & $475 \cdot 1^{\mathrm{a}}$ & $430 \cdot 2^{\mathrm{a}}$ & $17 \cdot 48$ & $0 \cdot 16$ & 0.01 & 0.01 \\
\hline Aspartic acid & 3.5 & 6.0 & 7.7 & 4.9 & $6 \cdot 6$ & 8.9 & 0.29 & 0.01 & 0.01 & 0.30 \\
\hline Asparagine & $59 \cdot 6^{d}$ & $74 \cdot 6^{\mathrm{C}}$ & $68 \cdot 8^{\mathrm{C}}$ & $78 \cdot 2^{c}$ & $98.2^{\mathrm{b}}$ & $110.7^{\mathrm{a}}$ & 3.69 & 0.01 & 0.01 & 0.01 \\
\hline Glutamic acid & $25 \cdot 6$ & $25 \cdot 9$ & $25 \cdot 1$ & 27.9 & 27.6 & $27 \cdot 7$ & 1.03 & 0.05 & 0.90 & 0.87 \\
\hline Glutamine & $626 \cdot 1$ & 733.9 & 619.0 & 533.0 & 691.9 & 599.3 & 19.03 & 0.01 & 0.01 & 0.14 \\
\hline Glycine & 383.1 & 392.0 & $460 \cdot 3$ & 276.7 & 329.6 & $429 \cdot 7$ & 18.02 & 0.01 & 0.01 & 0.05 \\
\hline Hydroxylysine & $9 \cdot 7^{b}$ & $16 \cdot 4^{\mathrm{a}}$ & $10.5^{\mathrm{b}}$ & $10 \cdot 9^{b}$ & $12 \cdot 1^{\mathrm{ab}}$ & $14 \cdot 0^{\mathrm{ab}}$ & $1 \cdot 26$ & 0.89 & 0.01 & 0.01 \\
\hline Hydroxyproline & $109 \cdot 8$ & 74.9 & 111.0 & $109 \cdot 0$ & $64 \cdot 2$ & $110 \cdot 3$ & 9.67 & 0.64 & 0.01 & 0.82 \\
\hline Proline & $217 \cdot 6^{\mathrm{c}}$ & $231.8^{\mathrm{bc}}$ & $266 \cdot 3^{\mathrm{ab}}$ & $168 \cdot 0^{d}$ & $226 \cdot 2^{b c}$ & $285.0^{\mathrm{a}}$ & 11.85 & 0.27 & 0.01 & 0.01 \\
\hline Serine & $179 \cdot 7^{\mathrm{a}}$ & $146 \cdot 0^{c}$ & $168 \cdot 7^{\mathrm{ab}}$ & $166 \cdot 5^{\mathrm{bc}}$ & $147 \cdot 3^{b c}$ & $194 \cdot 2^{\mathrm{a}}$ & 7.36 & 0.58 & 0.01 & 0.01 \\
\hline Tyrosine & 54.9 & 51.0 & 48.7 & 44.5 & 48.6 & $45 \cdot 6$ & 1.89 & 0.01 & $0 \cdot 19$ & 0.06 \\
\hline \multicolumn{11}{|l|}{ Others } \\
\hline Amino-butyric acid & $15 \cdot 4$ & 29.9 & $17 \cdot 1$ & $25 \cdot 9$ & $33 \cdot 1$ & $25 \cdot 2$ & 1.71 & 0.01 & 0.01 & 0.08 \\
\hline Carnosine & $39.7^{\mathrm{b}}$ & $41 \cdot 0^{\mathrm{b}}$ & $40 \cdot 2^{b}$ & $38.8^{\mathrm{b}}$ & $39.7^{b}$ & $47 \cdot 9^{\mathrm{a}}$ & 1.56 & 0.27 & 0.02 & 0.01 \\
\hline Citruline & 58.5 & 52.5 & $54 \cdot 1$ & $50 \cdot 0$ & 46.5 & $52 \cdot 7$ & 3.03 & 0.18 & 0.01 & 0.05 \\
\hline Cystathionine & $4 \cdot 2$ & 3.6 & 3.9 & $4 \cdot 0$ & $3 \cdot 1$ & 3.9 & 0.31 & 0.46 & 0.04 & 0.67 \\
\hline Ethanolamine & $15 \cdot 9^{c}$ & $23 \cdot 2^{a}$ & $14.9^{c}$ & $21 \cdot 2^{\mathrm{ab}}$ & $15 \cdot 5^{\mathrm{c}}$ & $17.9^{\mathrm{bc}}$ & 1.26 & 0.87 & 0.06 & 0.01 \\
\hline 1-Methyl-L-histidine & $14 \cdot 6^{\mathrm{C}}$ & $13 \cdot 1^{c}$ & $16 \cdot 0^{c}$ & $25 \cdot 0^{\mathrm{b}}$ & $27 \cdot 4^{\mathrm{b}}$ & $35 \cdot 2^{\mathrm{a}}$ & 1.58 & 0.01 & 0.01 & 0.01 \\
\hline 2-Methyl-L-histidine & $16 \cdot 1$ & $16 \cdot 3$ & $16 \cdot 3$ & $13 \cdot 7$ & $17 \cdot 4$ & $16 \cdot 5$ & 1.55 & 0.86 & 0.15 & 0.22 \\
\hline Ornithine & $16 \cdot 5^{\mathrm{bc}}$ & $23.0^{\mathrm{a}}$ & $17 \cdot 7^{\mathrm{bc}}$ & $13 \cdot 7^{c}$ & $25 \cdot 6^{\mathrm{a}}$ & $21 \cdot 4^{\mathrm{ab}}$ & 1.20 & 0.31 & 0.01 & 0.01 \\
\hline
\end{tabular}

${ }^{a-c}$ Within a row, means without a common letter differ (diet $\times$ time interaction; $P<0.05$ ), $n 39$.

differences due to exercise and diet, even though animals were balanced for these variables. Despite these limitations, the data presented herein reflects variations commonly faced in field research studies and in the pet exercising population. Another limitation of the present study is that, to our knowledge, this was the first research study to use a GPS device to provide performance data. This GPS device was developed to accurately track the location of hunting dogs and has been used in this regard for years, but has not been validated for use in a research setting. Because the device provides GPS-based location data every $15 \mathrm{~s}$ (including the initial location of the animal, the distance travelled and the amount of time needed to travel the distance), we were able to calculate distance run, and average and maximum speed during exercise bout.

Conclusions. In summary, feeding a nutrient-fortified diet resulted in greater plasma taurine concentration pre- and post-acute-exercise, and greater plasma BCAA:tryptophan post-exercise. While the latter has been related to delayed fatigue in response to exercise, the greater BCAA:tryptophan ratio in the present study did not affect athletic performance. In addition, no effect of diet was observed on the athletic performance. Similarly, plasma MDA concentration was not affected by exercise or dietary treatment. It is possible the exercise regimen used in the present experiment was not strenuous enough to pose a metabolic and oxidative challenge for the animals. However, future studies are warranted to investigate the effect of a nutrient-fortified diet in dogs undergoing repetitive exercise or a more vigorous and intense exercise regimen as they may impose a greater oxidative and metabolic stress to athlete dogs.

\section{Supplementary material}

The supplementary material for this article can be found at http://www.journals.cambridge.org/jns

\section{Acknowledgements}

The authors express gratitude to Hard Away Whitworth Hounds for their dogs and to A. Conner, S. Evely, and R. Garrett for their animal care and assistance. The Nutro Company provided funding for this research. M. R. C. G., A. N. B., A. J. F., Z. Y., B. J. M. and K. S. S. have no conflict of interest. R. A. C. and P. R. B. are employed by The Nutro Company. M. R. C. G., A. N. B., K. S. S. 
and P. R. B. designed the experiment. M. R. C. G. performed data collection, handling, and statistical analysis and wrote the manuscript. A. N. B. performed data collection and handling, and revised the manuscript. A. J. F and Z. Y. assisted in the amino acid analysis and amino acid data interpretation. R.A.C, B. J. M., K. S. S. and P. R. B. assisted in sample handling and revised the manuscript.

This paper was published as part of the WALTHAM International Nutritional Sciences Symposium Proceedings 2013, publication of which was supported by an unrestricted educational grant from Mars Incorporated. The papers included in these proceedings were invited by the Guest Editor and have undergone the standard journal formal review process. They may be cited.

\section{References}

1. Hill R (1998) The nutritional requirement of exercising dogs. J Nutr 128, 2686S-2690S.

2. Kronfeld DS, Ferrante PL \& Grandjean D (1994) Optimal nutrition for athletic performance, with emphasis on fat adaptation in dogs and horses. J Nutr 124, 2745S-2753S.

3. Piercy RJ, Hinchcliff KW, DiSilvestro RA, et al. (2000) Effect of dietary supplements containing antioxidants on attenuation of muscle damage in exercising sled dogs. Am J Vet Res 61, 438-1445.

4. Dunlap KL, Reynolds AJ \& Duffy LK (2006) Total antioxidant power in sled dogs supplemented with blueberries and the comparison of blood parameters associated with exercise. Comp Biochem Pbysiol 143, 429-434.

5. NRC (2006) Nutrient Requirements of Dogs and Cats. Washington, DC: The National Academies Press.

6. Laflamme DP (1997) Development and validation of a body condition score system for dogs. Canine Pract 22, 10-15.
7. Delaney SJ, Kass PH, Rogers QR, et al. (2003) Plasma and whole blood taurine in normal dogs of varying size fed commercially prepared food. J Anim Physiol Anim Nutr 87, 236-244.

8. Hamilton RS \& Rossell JB (1986) Analysis of Oils and Fats. London: Elsevier Applied Science, pp. 23-32.

9. McLellan CP, Lovell DI, Gass GC, et al. (2011) Biochemical and endocrine response to impact and collision during elite rugby league match play. J Strength Cond Res 25, 1553-1562.

10. Crnogaj M, Petleski R, Mrljak V, et al. (2010) Malondialdehyde levels in serum of dogs infected with Babesia canis. Vet Med 55, 163-171.

11. Artioli GG, Gualano AB, Smith A, et al. (2009) Role of beta-alanine supplementation on muscle carnosine and exercise performance. Med Sci Sports Exerc 42, 1162-1173.

12. Harris RC, Marlin DJ, Dunnet M, et al. (1990) Muscle buffering capacity and dipeptide content in the thoroughbred horse, greyhound dog and man. Comp Biochem Physiol A 97, 249-251.

13. She P, Zhou Y, Zhang Z, et al. (2010) Disruption of BCAA metabolism in mice impairs exercise metabolism and endurance. $J A p p l$ Physiol 108, 941-949.

14. De Palo EF, Gatti R, Capellin E, et al. (2001) Plasma lactate. GH and $\mathrm{GH}$ binding protein levels in exercise following BCAA. Amino Acids 20, 1-11.

15. Ferrando AA, Williams BD, Stuart CA, et al. (1995) Oral branchedchain amino acids decrease whole-body proteolysis. J Parent Enteral Nutr 19, 47-54.

16. Falavigna G, Junior JAA, Rogero MM, et al. (2012) Effects of diets supplemented with branched-chain amino acids on the performance and fatigue mechanisms of rats submitted to prolonged physical exercise. Nutrients 4, 1767-1780.

17. Blomstrand E, Hassmen P, Ekblom B, et al. (1991) Administration of branched-chain amino acids during sustained exercise - effects on performance and on plasma concentration of some amino acids. Eur J Appl Physiol 63, 83-88.

18. Kimball SR \& Jefferson LS (2006) Signaling pathways and molecular mechanisms through which branched-chain amino acids mediate translational control of protein synthesis. J Nutr $136,227 \mathrm{~S}-231 \mathrm{~S}$. 